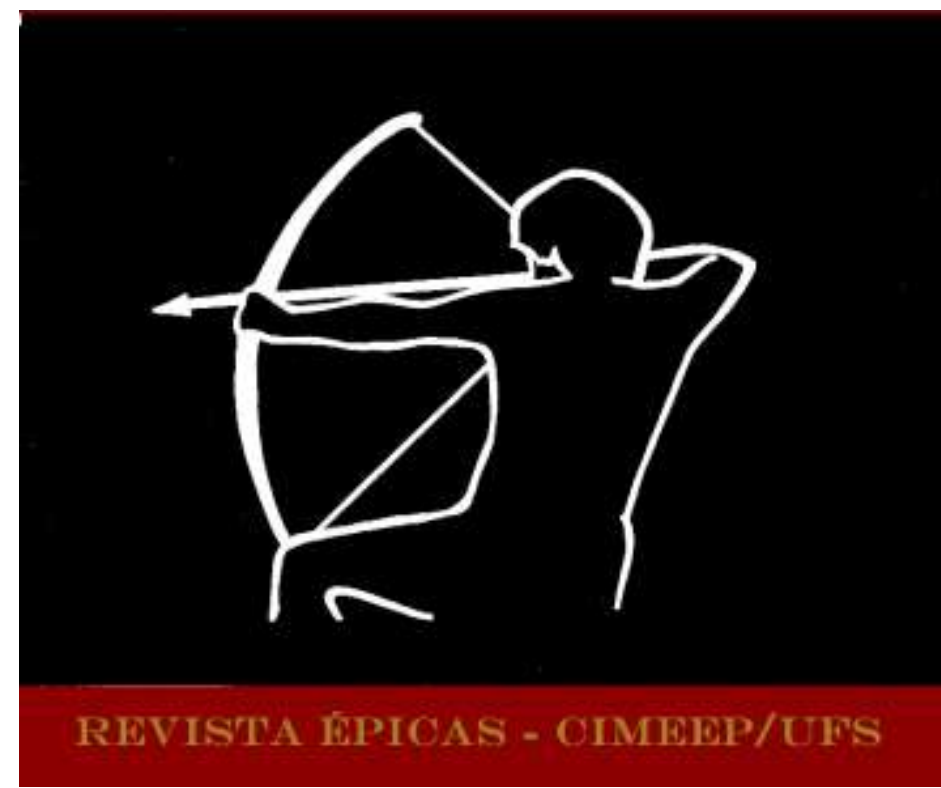

VIVEIROS, Ricardo. Arquitetura do tema, engenharia do poema: sonho e realidade na obra de João Cabral de Melo Neto. In: Revista Épicas. Ano 5, Número Especial 4, Março 2021, p. 40-50 . ISSN 2527-080X. DOI: http://dx.doi.org/10.47044/2527-080X.2021vNE4.4050

\title{
ARQUITETURA DO TEMA, ENGENHARIA DO POEMA: SONHO E REALIDADE NA OBRA DE JOÃO CABRAL DE MELO NETO
}

\author{
THEME ARCHITECTURE, POEMA ENGINEERING: DREAM AND REALITY \\ IN JOÃO CABRAL DE MELO NETO'S WORK
}

Ricardo Viveiros ${ }^{1}$

RV\&A Oficina de Comunicação

RESUMO: Este artigo refere-se à transcrição da comunicação realizada pela jornalista brasileiro Ricardo Viveiros por ocasião do I Seminário Internacional de Religião, Arte e Literatura, promovido pela Universidade Lusófona de Humanidades e Tecnologias e a Universidade de Lisboa, em 18 de novembro de 2020. Ricardo Viveiros aborda em sua comunicação aspectos do cotidiano de João Cabral de Melo Neto, que conheceu pessoalmente através de seu ofício de jornalista. Com muita sensibilidade traz curiosidades da vida do grande escritor brasileiro destacando sua crítica sutil, humor irônico e seu perfeccionismo.

Palavras-chave: João Cabral de Melo Neto. João Cabral. Literatura brasileira.

ABSTRACT: This article refers to the transcript of the communication made by the Brazilian journalist Ricardo Viveiros on the occasion of the 1st International Seminar on Religion, Art and Literature, promoted by the Lusophone University of Humanities and Technologies and the University of Lisbon, on November 18, 2020. Ricardo Viveiros addresses in his communication aspects of the daily life of João Cabral de Melo Neto, whom he met personally through his profession as a journalist. With great sensitivity he brings curiosities from the life of the great Brazilian writer, highlighting his subtle criticism, ironic humor and his perfectionism.

Keywords: João Cabral de Melo Neto. João Cabral. Brazilian literature.

\footnotetext{
1 Jornalista, professor e escritor, doutor em Educação, Arte e História da Cultura pela Universidade Presbiteriana Mackenzie; membro da Academia Paulista de Educação (APE) e da União Brasileira de Escritores (UBE). Autor de 49 livros, entre os quais $A$ vila que descobriu o Brasil (Geração), Educação S/A (Pearson), Justiça seja feita (Sesi-SP), O poeta e o passarinho (Biruta) e O menino que lia nuvens (Gaivota).
} 


\section{Introdução}

Muito boa tarde!

Abro minha palestra com absoluta gratidão pelo honroso convite para estar aqui, com todos vocês, nesta confluência de vários caminhos de uma língua que tem a mesma origem.

Nós, brasileiros, crescemos e somos educados olhando Portugal como nossa "mãe". E o curioso é que, mesmo sendo descendentes de outros povos, na conhecida miscigenação racial de nosso País, até os que não têm sangue luso entendem nossa terra como uma extensão de Portugal.

Mesmo que alguns vejam os conquistadores como mercenários que invadiram o Brasil em busca de riquezas, ninguém jamais poderá questionar que, embora com distintas culturas, o idioma que compartilhamos - com os naturais abrasileiramentos - é o mesmo. Tem igual berço, como está no soneto "Língua Portuguesa", do poeta Olavo Bilac: Última flor do Lácio, inculta e bela. Metáfora que nos une de maneira incontestável, mostrando a beleza da língua na interpretação por vezes rude do povo mais simples.

Assim, aqui e agora, faço virtual travessia do Oceano Atlântico em uma volta às raízes de nossa irmandade. Viajo nas asas mágicas da comunicação digital, quando a pandemia da Covid-19 nos rouba o prazer do convívio. A tecnologia nos permite, deste modo, comungar ideias transpondo a distância geográfica, unindonos na sensibilidade do tema.

E aqui estou, com muita alegria, para falar de um dos mais sérios e competentes estudiosos de nossa língua. Um escritor que, como eu, tem fortes laços com Portugal. Arquiteto e engenheiro da palavra escrita e falada, alguém que fez da poesia sua missão na vida - com muito talento, arte e responsabilidade.

Um artífice literário que soube equilibrar razão e emoção, revelando ao Brasil e ao mundo o conhecimento da sofrida realidade de nosso povo. A verdadeira vida de quem representa a maioria de nossa gente.

Vamos conversar sobre João Cabral de Melo Neto, homem e poeta que transcendeu limites e alcançou a imortalidade não apenas acadêmica, mas a que de fato lhe importava, dos seus apaixonados leitores por todo o mundo que fazem dele, geração após geração, um autor eterno.

E aqui tratamos o tema, por oportuna e relevante iniciativa dos organizadores deste seminário na comemoração dos 100 anos de João Cabral e de Clarice Lispector, neste feliz momento de falar, refletir e viver "Amores e desamores".

Meus parabéns à Universidade Lusófona e à Universidade de Lisboa, bem como às muitas instituições de educação e cultura, portuguesas e de vários países da Europa, que se uniram neste projeto de reconhecimento ao talento literário de dois encantadores de almas. Meus cumprimentos aos professores doutores das Comissões Organizadora e Científica deste SIRAL. E o meu cumprimento especial à professora doutora Lidice Meyer, 
educadora brasileira, que sempre nos brindou com seu brilho e conhecimento e, agora, para nosso orgulho, honra-nos também no meio acadêmico de Portugal e europeu.

Vou abordar um pouco da biografia do poeta, porque sua infância, juventude e maturidade estão intrinsicamente ligadas ao seu trabalho. A vivência - base do seu ofício de criador - moldou seu olhar sobre o mundo e o fez abordar, de modo único, o dia a dia do rural e do urbano na luta pela sobrevivência. João Cabral mostra o transcender às adversidades e como o povo sabe olhar com ternura a dureza da vida. A obra poética de João Cabral surge e se desenvolve entre a casa grande da fazenda, onde vivia com erudição, e a atual senzala dos novos "escravos", com os quais descobriu a beleza e a sinceridade da literatura popular.

Como veremos, João Cabral, que para alguns desatentos nunca escreveu poemas de amor, soube criar inspirados versos, por vezes aparentemente frios, sobre o amor ao próximo - sentimento em fase de perigosa extinção. Muitas vezes, presente no discurso e ausente na prática - algo que ele sempre criticou na política. Outro aspecto pouco comentado, porque não percebido, é a sutileza do poeta revelada em seu irônico humor. Em alguns de seus livros, como Morte e Vida Severina, O cão sem plumas e Dois parlamentos, existe um refinado humor ácido.

\section{Desenvolvimento}

João Cabral de Melo Neto nasceu na cidade do Recife, capital do Estado de Pernambuco, na região Nordeste do Brasil, em 9 de janeiro de 1920. Foi o segundo filho de Antônio Cabral de Melo e de Carmen Carneiro-Leão Cabral de Melo. Família nobre de agricultores e intelectuais. João Cabral é primo, por parte de pai, do poeta Manuel Bandeira, e por parte de mãe, do polímata Gilberto Freyre. Bandeira e Freyre são, como João Cabral, expoentes da cultura brasileira, notadamente o primeiro na poesia, e o segundo na Sociologia.

A infância rural, até os 10 anos de idade nos engenhos de açúcar do interior pernambucano e a juventude urbana, mais tarde na capital do estado, ofereceram ao poeta elementos fundamentais, preciosa matéria-prima para o seu trabalho literário. João Cabral estudou no tradicional Colégio dos Irmãos Maristas e, ao mesmo tempo, integrou a equipe juvenil do Santa Cruz Futebol Clube, pela qual foi campeão na categoria em 1935. O futebol sempre foi sua paixão. A música um tormento, era muito desafinado e passava vergonha nas aulas de canto. Por toda sua vida ficaria distanciado da música.

Entre a elite e o povo, experimentando a pureza do verde das plantações, dos riachos e dos animais, convivendo com a classe abastada na escola e com os menos favorecidos no esporte, João Cabral foi construindo, também com a leitura de bons livros, sua consciência política e social, encontrando e definindo o seu estilo de escrever. Contribuíram nesse sentido seus primeiros empregos: um na iniciativa privada e outro no serviço público, na Associação Comercial de Pernambuco e no Departamento de Estatística do Estado de Pernambuco, respectivamente. 
Entre os elegantes eventos sociais e os frios números da realidade, o poeta, ainda adolescente, acrescentou um componente incendiário ao seu cotidiano: passou a frequentar a roda literária e artística do charmoso Café Lafayette, uma esquina efervescente formada pelo encontro da Rua Primeiro de Março com a Rua do Imperador, no centro antigo do Recife. De dia convivia com empresários e políticos, à noite com intelectuais e prostitutas, lá conheceu o crítico Willy Lewin, o pintor Vicente do Rego Monteiro, o poeta Ledo Ivo, entre outros influenciadores.

O pai de João Cabral, homem lúcido, percebeu que o filho não seria usineiro como ele. Então o levou ao Diário de Pernambuco, do amigo Aníbal Fernandes. Também lúcido, o publisher foi sincero e disse que, com apenas 17 anos, João Cabral não tinha bagagem para escrever no jornal. E, muito menos, ser crítico literário como pretendia. Isso foi encarado pelo jovem, que desejava ser jornalista, como um desafio. E ele mergulhou na excelente biblioteca de Willy Lewin, onde havia obras de poetas e romancistas europeus, predominantemente franceses e ingleses, como Valéry e Mallarmé, Claudel e Joyce, Mauriac e Julien Green, Proust e Apollinaire, Kafka e D. H. Lawrence, André Breton e Jean Cocteau, Virgínia Woolf e Ezra Pound, além de livros dos surrealistas, que o atraíam bastante.

Como na roda do Café Lafayette quase todo mundo escrevia alguma coisa, em especial poesia, João Cabral achou seu caminho. E começou a poetar. Antes de mudar-se para o Rio de Janeiro, João Cabral participou, com Vicente do Rêgo Monteiro e Willy Lewin, da mudança da revista trabalhista Renovação, editada por uma central sindical, que acabou se tornando um veículo literário. Foi em 1943, já na Capital Federal do Brasil, que João Cabral definiu seu futuro ao enveredar pela poesia e pelo serviço público como formas de sonho e sustento.

Quando seguiu para o Rio de Janeiro, ele o fez contra a vontade de sua mãe. Foi tratar uma terrível dor de cabeça. Algo que, acreditava ele, teve origem em um choque durante uma partida de futebol. Sua mãe, contrariada, prometeu que nunca lhe escreveria. Passou o resto da vida perguntando por ele pelas cartas do marido, só para não descumprir a palavra dada.

Com mensagem de recomendação de Willy ao poeta Murilo Mendes, João Cabral chegou ao Rio de Janeiro. Mendes o recebeu muito bem e o apresentou aos poetas Carlos Drummond de Andrade e Jorge de Lima, este último médico. Contou-me João Cabral, entre muitas histórias, que o consultório de Lima, na agitada Cinelândia, então reduto boêmio no centro da Capital Federal, era um ponto de encontro de intelectuais e ficava bem próximo aos bares da moda, o "Vermelhinho" e o "Amarelinho". João Cabral reencontrou o primo Manuel Bandeira, que, além de perguntar muito sobre os parentes do Recife, porque veio menino para o Rio, também Ihe indicava bons livros.

João Cabral viajou por terra porque por mar havia o risco de bombardeio alemão. O mundo estava em plena Segunda Guerra Mundial, e o Brasil era inimigo do denominado eixo, formado por Alemanha, Itália e Japão. Foi uma viagem muito cansativa, que durou 13 dias do Recife ao Rio de Janeiro, utilizando trem, ônibus e barco (este último na travessia do Rio São Francisco). 
João Cabral prestou concurso para o Departamento Administrativo do Serviço Público (Dasp), uma espécie de centro de recursos humanos (recrutamento, seleção e admissão) de todo o funcionalismo federal do País. O órgão controlava os exames, as provas para ingressar no serviço público. Entrou como assistente de seleção. Assim, com o salário de servidor federal, mantinha-se como poeta. Mas não desistiu da ideia inicial, de prestar concurso para o Itamaraty, porque pretendia correr o mundo.

Aliás, o poeta contou-me um episódio muito divertido. Um primo havia prestado exame para fiscal de rendas e foi aprovado. Então, tentava convencê-lo a fazer o mesmo, o salário era bom. João Cabral lhe disse algo assim: "Rapaz, se eu passar para fiscal de rendas vão me mandar para o Piauí, mas, se eu for diplomata, o Itamaraty vai me mandar para Cádiz. Eu prefiro ir para a Espanha a ir para o Piauí.". Vale a explicação, para os que não conhecem o Brasil, o Piauí era na época um modesto estado do Nordeste brasileiro. Curioso dizer que muitos anos depois, o destino se encarregou de realizar o sonho do passado, de fato João Cabral foi enviado, como diplomata, a Cádiz.

Além dos europeus que o influenciaram, como os já mencionados e também o poeta e dramaturgo italiano Luigi Pirandello, João Cabral nunca renegou outras referências brasileiras como Murilo e Drummond. Tornou-se amigo de Drummond, que, segundo comentou em uma das conversas que tivemos, era uma pessoa estranha nos hábitos. Eu também convivi um tempo com Drummond e pude comprovar isso. Mas os dois foram muito íntimos, a ponto de Drummond ter sido padrinho do primeiro casamento de João Cabral.

Fato curioso, também relatado em conversas, é que Murilo era de direita e Drummond de esquerda, um católico e o outro ateu. E João Cabral se dava muito bem com ambos, mas havia um truque. Para evitar conflitos ideológicos que pudessem abalar a amizade entre todos, jamais tratavam de assuntos políticos. João Cabral era católico, mas revoltou-se com a catequização exagerada dos irmãos maristas. Também nunca gostou de política, algo que para ele funcionava na teoria e não na prática. E jamais gostou dos poetas parnasianos, que ele achava "melosos" demais.

Curioso ver que, embora se definisse como materialista, sempre acreditou na existência do inferno. E do modo mais tradicional, com caldeirões de água fervendo e demônios vermelhos armados de tridentes e torturando os pecadores. E quando comentava isso, interessante relatar, mesclava alegria e tristeza. Segundo ele, sempre estabelecia uma relação entre o inferno - que lhe desenharam os irmãos maristas, o que lhe despertava humor ácido - e o pesar pelo sofrimento do nordestino na terra seca e vermelha da caatinga, sem água e mergulhado na mais triste miséria. Abandonado à própria sorte pelas autoridades. A essência do que está no seu auto Morte e Vida Severina.

Já na longa e bem-sucedida carreira diplomática de João Cabral, depois que ingressou no Itamaraty, passando por mais de uma dezena de países, incluindo Portugal, o poeta foi vítima de uma trama política que o amargou muito, deixando-lhe marcas para sempre. Em um período em que escreveu para uns poucos jornais, 
entre eles a Última Hora, do polêmico Samuel Wainer, diário no qual também trabalhei, João Cabral publicou um artigo sobre a morte de Getúlio Vargas. Estampado na capa da edição do jornal, tornou-se um grande sucesso.

As pessoas recortavam o texto e o colavam nos postes pelas ruas do Rio de Janeiro. $\mathrm{O}$ artigo causou forte comoção popular. João Cabral foi taxado de comunista por Carlos Lacerda, editor da Tribuna da Imprensa, jornal que confrontava com a Última Hora. O poeta foi afastado de suas funções diplomáticas, processado por supostamente criar uma célula do Partido Comunista no Itamaraty, maldosa ilação de Lacerda. Mais tarde, ao ser perdoado, voltou ao serviço público na mesma posição. Uma coisa interessante, que pouca gente sabe, é que sendo diplomata, poeta e de fácil convívio com as pessoas de qualquer classe social, João Cabral era um homem tímido. Em certas ocasiões, recorria a uma taça de vinho ou a uma dose de uísque para descontrair e socializarse melhor nos eventos.

Depois de mostrar esse lado humano do poeta, os fundamentos que lhe deram material para expressar tantos belos e inquietantes sentimentos sobre a vida, vamos falar um pouco mais de sua vasta e relevante obra. Vamos abordar a "Arquitetura do tema, engenharia do poema: sonho e realidade na obra de João Cabral de Melo Neto", título que dá nome a esta nossa despretensiosa conversa que está merecendo a paciência de todos vocês.

João Cabral é um poeta bastante complexo, difícil, com estilo único, requer competência literária e cuidado na leitura de seus trabalhos. Ele sempre escreveu para quem gosta de ler, sabe ler e alcança o estilo sofisticado, que vai muito além das palavras. Contava João Cabral, sempre lembrado por Morte e Vida Severina, que nunca pretendeu escrever para teatro e que esse auto foi, pela primeira vez, algo que criou com o propósito de ser lido e apreciado pelas pessoas mais simples, não letradas.

Os versos são escritos com a emoção da sinceridade, uma fotografia da realidade vivida.

Observem, agora, o que retrata João Cabral quando do enterro de um trabalhador do campo, na interpretação de seus companheiros de luta na terra:

\footnotetext{
Essa cova em que estás, com palmos medida, é a conta menor que tiraste em vida.

É de bom tamanho, nem largo nem fundo, é a parte que te cabe deste latifúndio.

Não é cova grande, é cova medida, é a terra que querias ver dividida.
} 


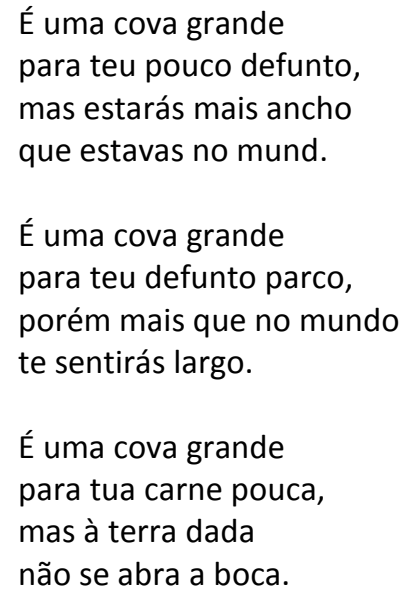

E por aí vão os versos de Morte e Vida Severina, todos de uma simplicidade tão forte quanto o que cada um deles desperta no leitor, ou no espectador, no contato com uma fria e duradoura realidade do homem do campo nordestino.

Nesse poema está clara a tentativa de João Cabral de escrever para o povo. Mas, em momento nenhum, ele perde a qualidade técnica e o estilo direto de provocar reações. Mantém o refinamento até no que pretendeu dar um tom mais popular.

Ouvi de Chico Buarque de Holanda um comentário de que foi muito, muito difícil mesmo musicar João Cabral. Primeiro, porque ele era muito jovem, nunca tinha feito isso e o poeta um nome já consagrado. Depois, porque havia versos que não tinham musicalidade. Ele fez cortes, alterações e foi, mais tarde, cobrado por João Cabral. Mesmo diante do estrondoso sucesso do trabalho em parceria...

Vale aclarar que Morte e Vida Severina foi uma encomenda que o poeta recebeu da dramaturga e diretora teatral Maria Clara Machado, filha do romancista mineiro Aníbal Machado, e proprietária do Tablado, um teatro no Rio de Janeiro que, também escola, trouxe à fama inúmeros artistas, diretores, cenógrafos, figurinistas e autores.

O prazo para João Cabral escrever era muito curto, seria um auto de Natal, e dezembro estava próximo. O poeta fez o trabalho correndo e a contragosto porque era um perfeccionista. Por isso, sempre achou a obra não tão bem-acabada, embora seja a que lhe trouxe mais fama. Muitos dizem que ele jamais gostou do texto, o que não é verdade porque ouvi dele próprio a afirmação contrária. Com seu jeito direto, comentava: "Ora, se eu não tivesse achado bom não teria deixado publicar."

Segundo João Cabral, ao escrever o poema, ele pensou nas pessoas ali retratadas, lá dos engenhos de sua infância, que deveriam assistir à montagem. E que gostariam tanto quanto dos livretos de cordel - literatura regional popular nordestina, em versos rimados, relatando aventuras fantásticas. Então, quando o texto ficou pronto, João Cabral o entregou ao poeta Vinicius de Moraes que, depois de ler, procurou-o entusiasmado. Fazendo muitos elogios. 
João Cabral ficou decepcionado. E disse a Vinicius que não havia escrito o livro para ele, mas sim para o público desletrado. E estava constatando, para sua tristeza, que os intelectuais é que gostaram da obra. Vale dizer que João Cabral considerava Vinicius de Moraes um excelente poeta.

Conto-Ihes uma divertida curiosidade. Como João Cabral não gostava de música, ficava aborrecido com a preferência do povo pelo Vinicius cantando samba ao Vinicius autor de tão belos poemas. Parecia a João Cabral um desperdício de talento, uma injustiça com o grande poeta que Vinicius era. E sobre Morte e Vida... é interessante destacar que Maria Clara Machado, que fez a encomenda do texto a João Cabral, não montou o auto em seu teatro. Achou que seria impossível o espetáculo.

Pode-se compreender essa questão do desafio de escrever para o povo simples. Há livros na bibliografia de João Cabral, como Uma faca só lâmina, que apenas estudiosos do idioma e do gênero poesia conseguem apreciar. Até por isso, essas obras não se tornaram populares, ficaram na primeira edição diferentemente de outras não herméticas.

Até quando João Cabral criou sobre uma de suas grandes alegrias, o futebol, o poema é uma perfeita obra de arquitetura, traz uma refinada e desafiadora engenharia. Havia, no Brasil dos anos 1970, um grande jogador de futebol, um craque, chamado Ademir da Guia. Mas era um jogador de estilo muito peculiar e de muita elaboração, por isso injustamente considerado lento, alguém que não vibrava e, portanto, não fazia sucesso aos olhos da grande maioria.

João Cabral escreveu um poema para Ademir da Guia, que está no livro Museu de Tudo. O poema, ironicamente, é tão hermético quanto o próprio estilo do jogador. Assim, não explicou o craque ao grande público. Aqui está para que entendam melhor o comentário:

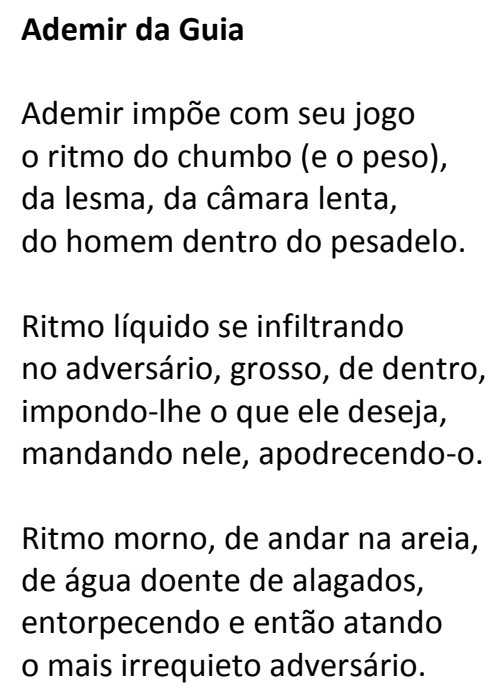

O melhor dessa história é que o jogador, imortalizado pelo grande poeta, não era de ler. Mas, comentou que jamais em toda a sua carreira havia sido "tão bem explicado". 
João Cabral rodou o mundo no seu ofício de diplomata, sempre promovendo a cultura, sempre criando formas de levar a literatura ao público, sempre apoiando artistas de diferentes áreas: músicos, pintores, cineastas, dramaturgos, não apenas escritores. Essa presença e atividade internacionais também contribuíram para que os seus livros alcançassem traduções em vários idiomas.

Ao conhecermos detalhes e curiosidades da vida do poeta, podemos, portanto, entender seu estilo de arquiteto e engenheiro de texto. Primeiro, desenhando a estrutura do poema, depois tratando as palavras como tijolos e unindo-as com a argamassa de uma composição elegante, refinada e capaz de tocar a alma das pessoas de maneira muito especial. Porque provoca, a cada verso, reflexões. Por fim, o pleno prazer da poesia que ele escrevia e reescrevia muitas vezes, levava dias, semanas e até meses antes de finalizar um texto.

O estilo é objetivo, racional e não permite pieguices. Parece gélido, mas é cheio de emoções bem contidas que afloram de acordo com a sensibilidade do leitor. As provocações, por vezes irônicas e humoradas, são fundamentadas em contrastes, dualidades do dia a dia de todos nós. A poesia de João Cabral comunica de modo direto, embora crie indagações, gere dúvidas sobre nós mesmos e a vida. Suas criações são construtivistas, com calculados toques de surrealismo, que ele guardou dos livros da rica biblioteca do amigo e orientador Willy, ainda nos bons tempos de sua amada Recife.

Interessante observar que, embora tenham coexistido vários poetas dentro do poeta João Cabral, ele não passou por fases, como acontece com muitos. João Cabral jamais renegou seus primeiros trabalhos, apenas gostaria de tê-los escrito com o conhecimento e a técnica já apurada da maturidade. Era, como antes comentado, um perfeccionista. O passado em João Cabral é referência para o presente planejar o futuro. Fica clara em sua obra a rejeição aos sentimentalismos, o permanente cuidado em não cair na armadilha de escrever versos melosos sobre o amor para entreter apaixonados. Seu poema é pedra lapidada que edifica reflexão sobre a realidade. Propõe transformações. Não ilude, mas também não tira a esperança.

João Cabral é o poeta brasileiro mais premiado no Brasil e no exterior, incluindo o Prêmio Luís de Camões, considerado o mais importante do universo lusófono. Além das muitas edições e reedições de seus 42 livros, no Brasil e em muitos idiomas por inúmeros países, está presente em mais de uma dezena de antologias e há cerca de 40 livros sobre sua vida e obra, um vasto trabalho de pesquisadores e críticos nacionais e estrangeiros.

O Teatro da Universidade Católica de São Paulo, o Tuca, produziu e apresentou, com música de Chico Buarque de Holanda, o auto Morte e Vida Severina. A montagem fez turnê de sucesso por diversas cidades brasileiras, depois indo para a Europa, onde, no Festival de Nancy, na França, João Cabral foi premiado como Melhor Autor Vivo. A turnê seguiu depois para a capital, Paris, e mais tarde foi a Lisboa, Coimbra e Porto, em Portugal. E o auto continua sendo montado por todo o mundo. O poema já ultrapassou cem edições em livro e foi transposto para história em quadrinhos, cinema e televisão, além do teatro. 
João Cabral foi eleito para a Academia Pernambucana de Letras e para a Academia Brasileira de Letras. Nunca se esqueceu de suas raízes, que sempre fez questão de ressaltar com orgulho. Certa vez, disse ter muita facilidade para aprender idiomas, mas, ao falar qualquer um deles, o sotaque era pernambucano.

O poeta foi fascinado por História. As origens, o desenrolar dos fatos, as transformações empreendidas pelo tempo o atraiam. Tinha muitos planos de escrever sobre o passado. Exemplo disso é o Auto do Frade, que escreveu nos anos 1980 sobre Frei Caneca - injustiçado personagem de nossa história. Entretanto, o destino foi traiçoeiro com João Cabral de Melo Neto. O poeta desde menino sofreu de uma insuportável dor de cabeça, como comentei no início, até descobrir que estava acometido de uma doença degenerativa que lhe tiraria a visão.

Imaginem o que significa para alguém que lia por horas todos os dias, como prazer e exercício de vida, perder a visão. Somou-se à doença e à cegueira uma compreensível depressão, que foi consumindo sua qualidade de vida nos últimos anos daquele que seria o primeiro Prêmio Nobel do Brasil. Estava concorrendo com muitas chances, indicado por instituições culturais de vários países, quando morreu isolado de si mesmo, segurando a mão de sua amada Marly. O Nobel havia mudado suas regras, passando a ser entregue apenas aos vivos, tirando não apenas de João Cabral de Melo Neto, mas de todos nós, esse justo reconhecimento.

\title{
Considerações finais
}

Foi-se o homem, ficou o poeta vivo em sua obra e, assim, eterno. Como prova disso, encerro esta palestra com um poema quase desconhecido daquele que fez da imagem uma arquitetada construção e da linguagem um ato de amor. Observem como o poeta relata a experiência do sonho, durante o sono, acontecendo dentro do poema:

\author{
Homem falando no escuro \\ Dentro da noite ao meu lado \\ Grandes contemplações silenciosas; \\ Dentro da noite, dentro do sonho \\ Onde os espaços e o silêncio se confundem. \\ Um gesto corria do princípio \\ Batendo asas que feriam de morte. \\ Eu me sentia simultaneamente adormecer \\ E despertar para as paisagens mais quotidianas. \\ Não era inconfessável que eu fizesse versos, \\ Mas juntos nos libertávamos a cada novo poema. \\ Apenas transcritos eles nunca foram meus, \\ E de ti nada restava para as cidades estrepitosas. \\ Só os sonhos nos ocupam esta noite, \\ Nós dois juntos despertamos o silêncio. \\ Dizia-se que era preciso uma inundação, \\ Mas nem mesmo assim uma estrela subiu.
}


Muito obrigado!

Espero em breve rever Portugal e sua gente que, há mais de meio século, seduz e encanta este seu fã incondicional. 